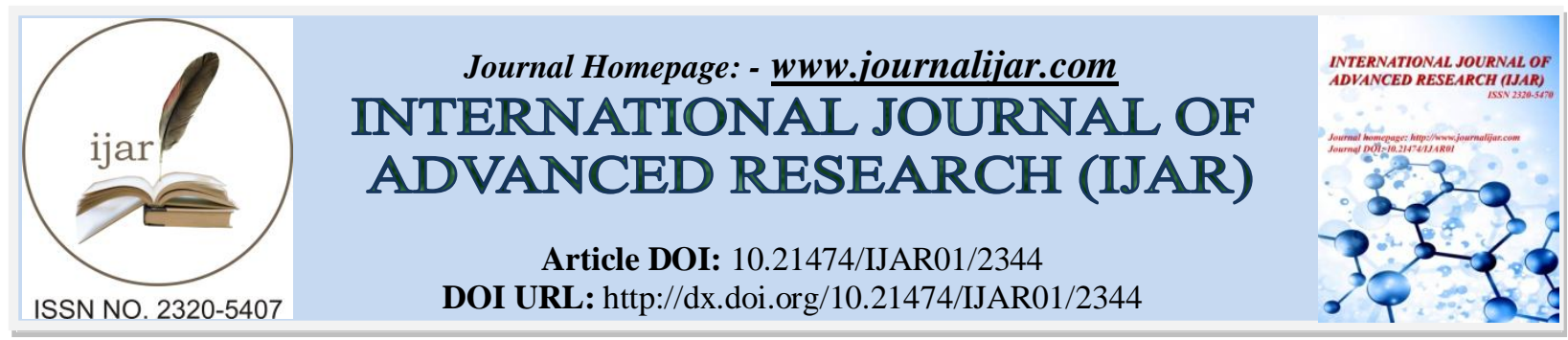

RESEARCH ARTICLE

\title{
A STUDY OF RELATIONSHIP BETWEEN HARDINESS AND PSYCHOLOGICAL WELL-BEING IN UNIVERSITY STUDENTS.
}

Touseef Rizvi.

\section{Manuscript Info}

Manuscript History

Received: 30 September 2016

Final Accepted: 30 October 2016

Published: November 2016

Key words:-

Hardiness, Psychological Well-being, Autonomy, Self-Acceptance.

\begin{abstract}
Previous research has found that hardiness is related to psychological well-being and lower levels of stress. This study examined the relationship of hardiness and psychological well-being in university students. The sample of the study consisted of 400 students studying in different departments of University of Kashmir, completing the sample survey packets comprising of Psychological Hardiness Scale (Betz \& Campbell, 2003) and Ryff's Psychological Well-being Scale (1995). The results of the study revealed that hardiness is significantly and positively correlated with all six dimensions of psychological wellbeing viz Autonomy $(\mathrm{r}=0.22, \mathrm{p}<0.001)$, Environmental Mastery $(\mathrm{r}=0.27, \mathrm{p}<0.001)$, Personal Growth $(\mathrm{r}=0.20, \mathrm{p}<0.001)$, Positive Relation with Others $(0.12, p<0.05)$, Purpose in Life $(r=0.21, p<0.001)$, Self-Acceptance $(\mathrm{r}=0.26, \mathrm{p}<0.001)$. The results of this study are consistent with the previous research, suggesting that hardiness has an important relationship with psychological well-being.
\end{abstract}

Copy Right, IJAR, 2016,. All rights reserved.

\section{Introduction:-}

In the twenty-first century, a group of psychologists have found that much of the intellectual energy of man is spent on the positive aspects of his experience (Myers, 2000). So one of the issues that in recent decades have attracted the attention of many, is positive psychology oriented (Seligman et al., 2000). This approach focuses on individual capabilities and believes that psychology aims to promote the hidden talents of his life. Today, a new perspective on the health-related sciences and in psychology in particular emerging and expanding is growing which aim is to focus on health, well-being and explain the nature of psychological well-being.

Based on the model of psychological well-being Ryff consists of 6 factors. Self- acceptance (having a positive attitude to itself), a positive relationship with others (warm and friendly relations and the ability to empathize with others), autonomy (independence and ability to stand in the face of social pressures), Purpose Driven Life (having a purpose in life and meaning to it) personal growth (a feeling of continuous growth) and control over the environment (ability to manage the environment). Ryff's model is widely considered in the world. Psychological hardiness of Kobasa was initially considered as a set of personality characteristics that in the face of stressful life events was considered as a source of strength, as well as the protective shield and individuals so that they can deal efficiently with the challenges and pressures of life. Kobasa, et al. (1982) found that people possessing hardiness traits became ill less often and had the ability to turn stressful life events into opportunities for personal growth and development. In a study comparing hardiness and stress among highway patrol officers, Hills and Norvel (1991) reported that the presence of high levels of hardiness exerted clear main effects in the prediction of reduced stress, burnout, and illness. 
Many researches have been done in the field of relationship of mental health with personality features such as psychological hardiness (Ghorbani, Watson \& Morris, 2000) and self-efficacy (Tong \&Shong, 2004). One of the personality variables which have relationship with psychological well-being is hardiness. The research have been done in the field of hardiness during the past two decades could confirm the theory of Kobasa on the positive effect of this factor on welfare of individuals in confrontation with stressful events of life (Baccarat et. al. 2008).Findings of Bartone, Ersano, RaitoIngraha (as cited in Thomas \&Seigel, 2006) indicated that psychological hardiness has a negative relationship with depression and post-damage stress. This study was conducted with the aim to find out the relationship between hardiness and psychological well-being in university students.

Method:-

SAMPLE: For the present study sample consisted of 400 students of Kashmir University. Students were from different courses offered by the university, within the age range of 20-24 years.

Brief description of the sample given below

\begin{tabular}{|l|l|l|l|}
\hline Gender & Male $=133$ & Female=267 & 400 \\
\hline Family type & Nuclear $=268$ & Joint $=132$ & 400 \\
\hline Residence & Rural =257 & Urban =143 & 400 \\
\hline Parental Occupation & Government =196 & Private =204 & 400 \\
\hline
\end{tabular}

\section{Instrumentation:-}

For the present study, following tools were used to collect data.

Psychological Wellbeing Scale (Ryff, 1995)consists of 42 statements dealing with how one feels about himself and his life. These statements are to be responded on a 6 point scale assessing six dimensions of psychological wellbeing propounded by Ryff.

Psychological Hardiness Scale (Betz \& Campbell, 2003)is a 20-item scale designed to measure attitudes reflecting psychological hardiness. Higher scores reflect higher levels of psychological hardiness. These statements are to be responded on a 5 point scale including strongly disagree (1), disagree (2), Neutral (3), Agree(4) and Strongly agree(5). Reliability of Betz \& Campbell's Psychological Hardiness scale is 0.92.

\section{Procedure:-}

In order to get the required data, the researcher approached students of various departments of Kashmir University. Before administering the study instruments, the researcher had an interaction with the respondents in order to make them aware about the purpose of the study. Then the questionnaires were handed over to the respondents and were asked to follow necessary instructions to fill them without hurry. They were requested to be open, easy going and sincere in giving their responses. The subjects were assured that their response will be kept highly confidential and will be used only for research purpose.

\section{Results and interpretation:-}

Table 1:- Frequency distribution of University Students with respect to Their Dimensions of Psychological WellBeing

\begin{tabular}{|l|l|l|l|l|}
\hline Psychological wellbeing & Levels & Range & Frequency & Percentage \\
\hline Dimension & & & & \\
\hline Autonomy & Low & $8-15$ & 5 & 1.25 \\
\cline { 2 - 5 } & Average & $16-34$ & 357 & 89.25 \\
\cline { 2 - 5 } & High & $35-42$ & 38 & 9.50 \\
\hline \multirow{5}{*}{ Environmental mastery } & Low & $8-15$ & 4 & 1.00 \\
\cline { 2 - 5 } & Average & $16-34$ & 376 & 94.00 \\
\cline { 2 - 5 } & High & $35-42$ & 20 & 5.00 \\
\hline \multirow{5}{*}{ Personal growth } & Low & $8-15$ & 1 & 0.25 \\
\cline { 2 - 5 } & Average & $16-34$ & 333 & 83.25 \\
\cline { 2 - 5 } & High & $35-42$ & 66 & 16.50 \\
\hline Positive relations & Low & $8-15$ & 1 & 0.25 \\
\cline { 2 - 5 } & Average & $16-34$ & 359 & 89.75 \\
\cline { 2 - 5 } & High & $35-42$ & 40 & 10.00 \\
\hline Purpose in life & Low & $8-15$ & 1 & 0.25 \\
\hline
\end{tabular}




\begin{tabular}{|l|l|l|l|l|}
\hline & Average & $16-34$ & 317 & 79.25 \\
\cline { 2 - 5 } & High & $35-42$ & 82 & 20.50 \\
\hline \multirow{3}{*}{ Self-acceptance } & Low & $8-15$ & 1 & 0.25 \\
\cline { 2 - 5 } & Average & $16-34$ & 326 & 81.50 \\
\cline { 2 - 5 } & High & $35-42$ & 73 & 18.25 \\
\hline
\end{tabular}

The table 1 shows frequency distribution of sample group with respect to various levels of psychological wellbeing.. As it is evident from the table that out of the total sample (400), 5(1.25\%); 4(1.00\%); 1(0.25\%); $1(0.25 \%)$; $1(0.25)$ and 1(0.25\%)are low, 38(9.50\%); 20(5.00\%); 66(16.50\%); 40(10.00\%); 82(20.50\%) are on medium level while as 38(9.50\%), 20(5\%), 1(0.25\%), 1(0.25\%), 82(20.50\%), 73(18.25\%) are on high level of Autonomy, Environmental Mastery, Personal Growth; Positive Relations; Purpose In Life and Self-Acceptance respectively.

Table 2:- showing frequency distribution of sample group with respect to the hardiness

\begin{tabular}{|l|l|l|l|l|}
\hline & & & $\mathrm{n}$ & $\mathrm{f}$ \\
\hline \multirow{3}{*}{ Psychological Hardiness } & Low & $<54$ & 44 & 11.0 \\
\cline { 2 - 5 } & Average & $54-68$ & 303 & 75.8 \\
\cline { 2 - 5 } & High & $>68$ & 53 & 13.2 \\
\hline
\end{tabular}

With respect to hardiness, the table shows that of the total sample of 400, 44(11.0\%) fall in low level, 303 (75.8\%) fall in medium level and 53(13.2\%) fall in high level of Psychological hardiness.

Table 3:- showing correlation between dimensions of Psychological wellbeing and Psychological hardiness of university students

\begin{tabular}{|l|l|}
\hline Psychological well-being & Psychological Hardiness \\
\hline Autonomy & $.299^{* *}$ \\
\hline Environmental mastery & $.271^{* *}$ \\
\hline Personal growth & $.207^{* *}$ \\
\hline Positive relation & $.128^{*}$ \\
\hline Purpose in life & $.215^{* *}$ \\
\hline Self-acceptance & $.267^{* *}$ \\
\hline
\end{tabular}

$* * \mathbf{p} \leq \mathbf{0 . 0 1}, * \mathbf{p} \leq \mathbf{0 . 0 5}$

Table 3 presents correlation between dimensions of Psychological wellbeing and Psychological hardiness. From the table it is evident that all the dimensions of Psychological well-being are significantly and positively correlated with Psychological hardiness.

\section{Discussion:-}

Given the increasing voluminous research on influence of hardiness on human behaviour in general and mental health in particular, the present endeavour was an attempt to assess the relationship of psychological hardiness with psychological well-being of university students. While analyzing the relationship between psychological wellbeing and psychological hardiness results revealed there is a significant correlation between dimensions of psychological wellbeing and psychological hardiness, which is supported by Kermani\&Mahani (2015), Skomorovsky \& Sudom.(2011), Mostafaei, (2012).

\section{References:-}

1. Baccarat, M. A., Salehi, Kh.,M., ShahMohammadi, H., Nadali, O., \&Zebardast, (2008)."The relationship between resistance and hardiness with sporting success and mental health of athletes".Contemporary psychology journal. 2, 38-49.

2. Betz, N. E., \& Campbell, C. (2003).Self-efficacy and personality correlates of instrumentality.Unpublished manuscript.

3. Ghorbani, N., Watson, P. J., \&Morris, R. J. (2000). "Personality, Stress and Mental Health: evidence of relationship a sample ofIranian managers". Personality and Individual Differences. 28, 647-657.

4. Hills, H., \&Norvell, N. (1991).An examination of hardiness and neuroticism as potential moderators of stress outcomes.Behavioral Medicine, 17(1), 31 -38. 
5. Kermani, G.N.,\&Mahani, Z.B.N. (2015).Relationship between psychological hardiness, their resiliency and hope to psychological well-being of nursing students of Kerman Razi University in the academic Year 20142015.Jurnal UMP Social Sciences and Technology Management 3(3), 193-196.

6. Kobasa, S.C. (1979). Personality and resistance to illness.American Journal of Community Psychology, 7,413423.

7. Maddi, S. R., \&Khoshaba., D. M. (1994).“Hardiness and Mental Health”.Journal Of Personality Assessment. 63, 265-274.

8. Mostafaei, A. (2012). The relationship between stress and mental health in university students.Annals of Biological Research, 3 (7), 3468-3473.

9. Myers, D. G. (2000).The funds, friends, and faith of happy people.American Psychologist, 55, 56-67.

10. Ryff, C. D., \& Keyes, C. L. M. (1995). The structure of psychological well-being revisited. Journal of Personality and Social Psychology, 60, 719-727.

11. Ryff, C.D. (1995). Psychological Well-Being in Adult Life. Current Directions in Psychological Science, 4(4), pp. 99-104.

12. Seligman, M. E. P., Csikszentmihalyi, M. (2000). Positive psychology: An introduction. American Psychologist, 55, 5-14.

13. Skomorovsky, A., \&Sudom, K. (2011).Role of hardiness in the psychological well-being of Canadian Forces officer candidates.Mil Med, 176(1), 7-12.

14. Thomas, J.C., \& D. I. Segal.(2006). "Comprehensive Hand book of Personality and Psychopathology. New Jersey. John Wiley \& Sons, Inc.

15. Tong,Y., \&Shong, S. (2004). "A Study on General Self-Efficacy and Subjective Well-Being of low SES College Students in a Chinese university".College Student Journal.38, 4637-642. 